\title{
Numerical Simulation of Continuous RC Slabs Strengthened using NSM Technique
}

\author{
J.A.O Barros \& G. Dalfré \\ University of Minho, Guimarães, Portugal \\ J.P. Dias \\ Civitest Company, Braga, Portugal
}

\begin{abstract}
The effectiveness of the Near Surface Mounted (NSM) technique for the increase of the flexural resistance of reinforced concrete (RC) beams and slabs was already well proved. The NSM technique is especially adapted to increase the negative bending moments of continuous (two or more spans) RC slabs. However, the influence of the NSM strengthening on the moment redistribution capability of RC structures should be investigated. Recently, an exploratory experimental program was conducted to assess the level of moment redistribution that can be obtained in two span RC slabs strengthened with NSM strips for negative bending moments. To help the preparation of an extensive experimental program in this domain, the values of the parameters of a constitutive model, implemented into a FEM-based computer program, were calibrated from the numerical simulation of these tests. The main aspects of the experimental program are presented, the numerical model is briefly described and the numerical simulations are presented and analyzed.
\end{abstract}

\section{INTRODUCTION}

When an existing continuous $\mathrm{RC}$ structure is strengthened with Fiber Reinforced Polymer (FRP) materials, its ductility and "plastic" rotation capacity may be restricted or even extinct, due to, principally, the linear-elastic stress-strain response of the FRP up to its brittle failure (Arduini et al. 1997, Casadei et al. 2003). As flexural members retrofitted with externally bonded reinforcing (EBR) technique tend to fail by brittle premature plate debonding, well before the FRP tensile strength capacity is reached, the ductility, particularly the plastic rotation capacity, is severely reduced, which decreases the available degree of moment redistribution (Oehlers et al. 2004a). The tests of El-Refaie et al. (2003a, 2003b), Ashour et al. (2004) and Oehlers (2004a) show that, in general, premature debonding of the EBR strengthening systesm is the dominant failure mechanism. However, according to the approach used by these authors to quantify the moment redistribution, significant moment redistribution was obtained in the tests (El-Refaie et al. 2003a, Oehlers et al. 2004a/2004b, Oehlers et al. 2006, Liu et al. 2006a), which contradicts the existing design guidelines (Concrete Society 2000, fib 2001, ACI 2002) that suggest that moment redistribution should not be allowed for RC members strengthened with EBR technique.

On the other hand, tests on simply supported RC members strengthened with Near Surface Mounted
(NSM) strips (Hassan \& Rizkalla 2003, Täljsten et al. 2003, Barros \& Fortes 2005, Barros et al. 2006) have shown that NSM strengthening elements debond or fail at much higher relative strain levels than EBR strengthening systems, therefore, in general, NSM strengthened members are expected to be much more ductile than EBR strengthened members. In addition, NSM strengthening installation procedures are easier and faster to apply than the ones of EBR technique (Täljsten et al. 2003). Therefore, NSM technique is recommended for strengthening negative moment regions, since for this application the NSM technique can be restricted to open slits and fix, with an adhesive, the FRP strips to the concrete substrate.

On the topic of moment redistribution of statically indeterminate RC members strengthened with NSM technique, the first preliminary studies were conducted at the Adelaide University, in Australia (Liu et al. 2006b). A significant amount of moment redistribution was attained with NSM, when compared with EBR technique. With the final purpose of establishing design guidelines for the NSM flexural strengthening of continuous RC structures, an exploratory experimental program was recently conducted (Bonaldo 2008). In this program the level of moment redistribution that can be obtained in two span RC slabs strengthened with NSM strips for negative moments was assessed. To help on the 
preparation of an extensive experimental program in this domain, the values of the parameters of a constitutive model, implemented into the FEMIX software (Sena-Cruz et al. 2007), a FEM-based computer program, were calibrated from the numerical simulation of these tests. This model is able of simulating the concrete crack initiation and crack propagation, the nonlinear concrete compression behavior, the elastoplastic behavior of steel reinforcements and the elastic-brittle failure behavior of FRP elements. The present work resumes the experimental program (more details can be found in Bonaldo (2008)), and describes and appraises the performance of the numerical model.

\section{EXPERIMENTAL PROGRAM}

\subsection{Slab specimens and strengthening technique}

According to CEB-FIB Model Code (1993), the coefficient of moment redistribution, $\delta=\mathrm{M}_{\text {red }} / \mathrm{M}_{\text {elas }}$, is defined as the relationship between the moment in the critical section after redistribution $\left(M_{\text {red }}\right)$ and the elastic moment $\left(M_{\text {elas }}\right)$ in the same section, calculated according to the theory of elasticity, while $M R=(1-\delta) \times 100$ is the moment redistribution percentage. To assess the influence of NSM CFRP strips on the moment redistribution ability of continuous RC slabs, an experimental program composed of nine $120 \times 375 \times 5875 \mathrm{~mm}^{3} \mathrm{RC}$ two-way slabs was carried out (Fig. 1), three of them were unstrengthened RC slabs forming a control set (SL15, SL30 and SL45), and six slabs were strengthened with CFRP strips according to the NSM technique (SL15s25, SL15s50, SL30s25, SL30s50, SL45s25 and SL45s50). The notation adopted to identify each slab specimen is SLxsy, where SL is the slab strip base, $\mathrm{x}$ is the moment redistribution percentage, MR, $(15 \%, 30 \%$ or $45 \%)$, s means that the slab is strengthened, and y is the increase of negative moment of the slab cross section at its intermediate support $(25 \%$ or $50 \%)$. Steel bars with nominal diameters of $8 \mathrm{~mm}$ and $12 \mathrm{~mm}$ were used for the longitudinal reinforcement. The concrete cover thickness is about $26 \mathrm{~mm}$.

Due to space limitation, this paper only deals with the series SL15s25, but the entire experimental program is treated in detail by Bonaldo (2008) and all the simulations can be found in Dalfré \& Barros (2008).

\subsection{Measuring Devices}

To measure the deflection of the slabs, six displacement transducers were applied (see Figure 2).

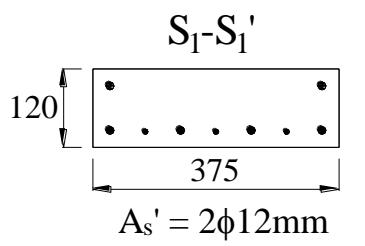

$\mathrm{A}_{\mathrm{s}}=4 \phi 12 \mathrm{~mm}+3 \phi 8 \mathrm{~mm}$

$\left(\mathrm{S}_{2}-\mathrm{S}_{2}\right)_{\mathrm{S} 25}$

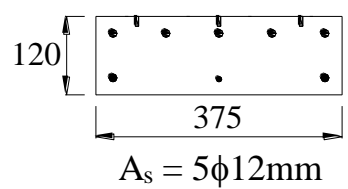

$\mathrm{A}_{\mathrm{s}}{ }^{\prime}=2 \phi 12 \mathrm{~mm}+1 \phi 8 \mathrm{~mm}$

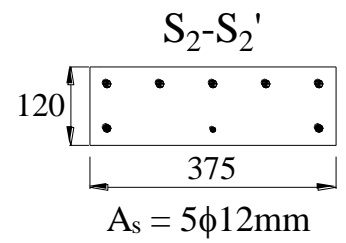

$\mathrm{A}_{\mathrm{s}}{ }^{\prime}=2 \phi 12 \mathrm{~mm}+1 \phi 8 \mathrm{~mm}$

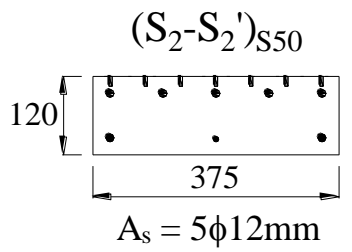

$\mathrm{A}_{\mathrm{s}}{ }^{\prime}=2 \phi 12 \mathrm{~mm}+1 \phi 8 \mathrm{~mm}$
Figure 1. Cross-section dimensions, see also figure $2\left(A_{s}^{\prime}-\right.$ top reinforcement; $A_{s}$ - bottom reinforcement).

The LVDTs 60541 and 18897, positioned at the slab mid-spans, were also used to control the test. Ten electrical resistance strain gages were installed on the internal steel reinforcement at the central support (SG1 to SG7) and under line loads (SG8 to SG10) to measure the strains in the steel reinforcements at critical regions. Six strain gages (SG11 to SG16) were also bonded on concrete surface to determine the maximum concrete compressive strain. Finally, three strain gages were installed at one CFRP strip (SG17, SG18 and SG19) to evaluate the strain variation along the strip.

\section{NUMERICAL SIMULATION}

\subsection{Constitutive laws}

According to the present model, a concrete slab is considered a plane shell formulated under the Reissner-Mindlin theory (Barros 1995). In order to simulate the progressive damage induced by concrete cracking and concrete compression nonlinear behavior, the shell element is discretized in layers. Each layer is considered in a state of plane stress.

The incremental strain vector derived from the incremental nodal displacements obtained under the framework of a nonlinear FEM analysis is decomposed in an incremental crack strain vector, $\Delta \underline{\varepsilon}^{c r}$, and an incremental strain vector of the concrete between cracks, $\Delta \underline{\varepsilon}^{c o}$. This last vector is decomposed in an elastic reversible part, $\Delta \underline{\varepsilon}^{e}$, and an irreversible or plastic part, $\Delta \underline{\varepsilon}^{p}$, resulting

$\Delta \underline{\varepsilon}=\Delta \underline{\varepsilon}^{c r}+\Delta \underline{\varepsilon}^{c o}=\Delta \underline{\varepsilon}^{c r}+\Delta \underline{\varepsilon}^{e}+\Delta \underline{\varepsilon}^{p}$

The incremental stress vector can be computed from the incremental elastic strain vector,

$\Delta \underline{\sigma}=\underline{D}^{c o} \Delta \underline{\varepsilon}^{c o}$ 

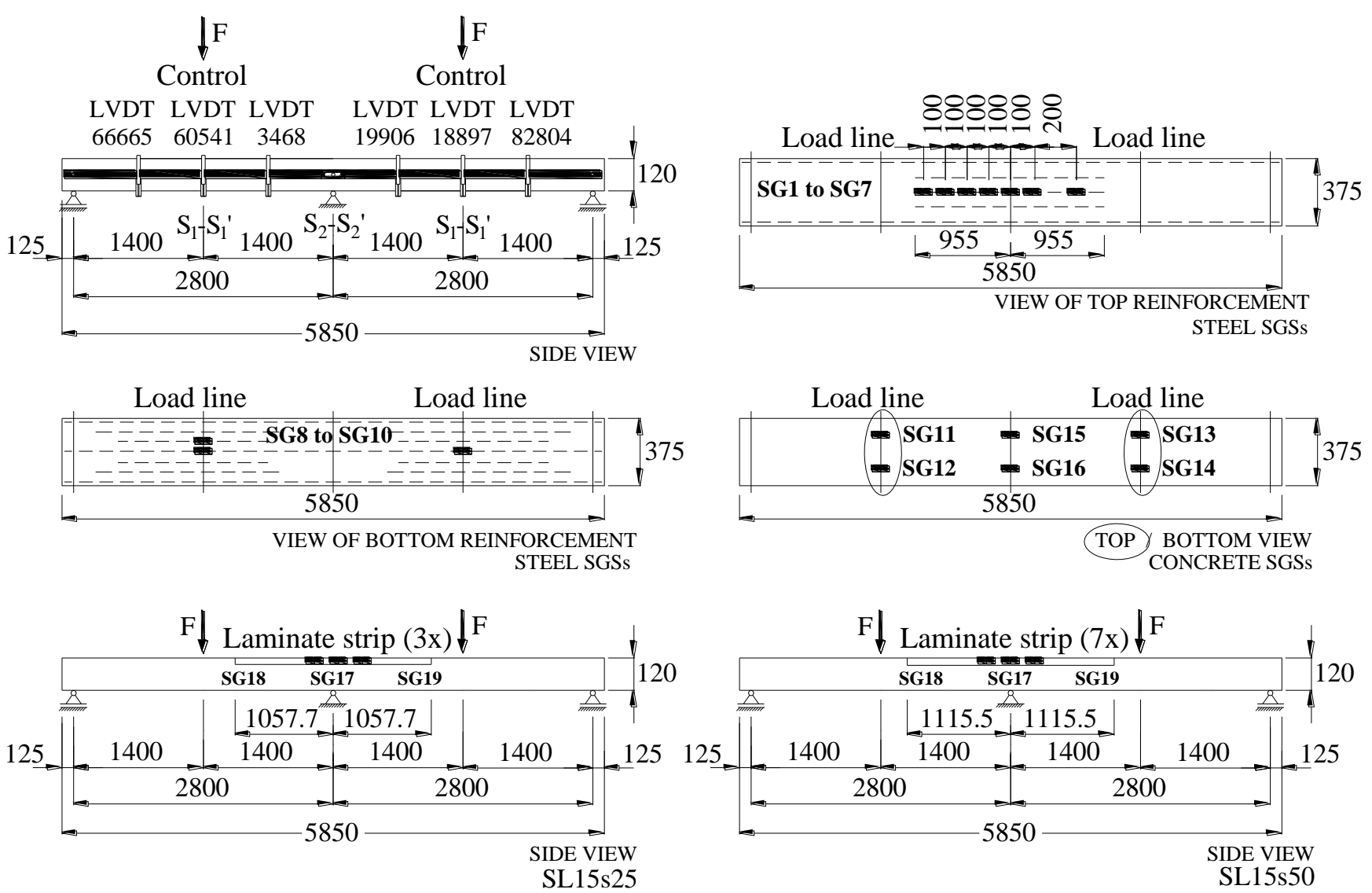

Figure 2. Arrangement of displacement transducers and strain gages.

$\underline{H}=\left(\left[\underline{D_{m b}^{e c o}}\right]^{-1}+h_{c} \Delta \lambda \frac{\partial^{2} f}{\partial \underline{\sigma^{2}}}\right)^{-1}$

where $\underline{D}^{c o}$ is the concrete tangent constitutive matrix,

$\underline{D}^{c o}=\left[\begin{array}{cc}\underline{D}_{m b}^{c o} & \underline{\emptyset} \\ \underline{\emptyset} & \underline{D}_{s}^{c o}\end{array}\right]$

with $\underline{D}_{m b}^{c o}$ and $\underline{D}_{s}^{c o}$ being the in-plane and the out-ofplane shear stiffness matrices, respectively. In the present model, concrete behavior is assumed linear elastic in terms of out-of-plane shear. Therefore, the concrete nonlinear behavior is only considered in the $\underline{D}_{m b}^{c o}$ constitutive matrix.

For linear elastic uncracked concrete, $\underline{D}_{\mathrm{mb}}^{\mathrm{co}}$ is designated by $D_{m b}^{e c o}$, which is defined elsewhere (Barros \& Figueiras 2001). For the case of cracked concrete with concrete between cracks exhibiting an elasto-plastic behavior, $D_{m b}^{c o}$ of (3) is replaced by $\underline{D}_{m b}^{\text {epcrco }}$ (Sena-Cruz et al. 2004):

$\underline{D}_{m b}^{c o} \Rightarrow \underline{D}_{m b}^{e p c r c o}=\underline{D}_{m b}^{e p c o}-\underline{D}_{m b}^{e p c o}\left[\underline{T}^{c r}\right]^{T}\left(\underline{D}^{c r}+\right.$ TcrDmbepcoTcrT-1TcrDmbepco

(4)

where

$\underline{D}_{m b}^{e p c o}=\underline{H}-\frac{\underline{H} \frac{\partial f}{\partial \underline{\sigma}}\left(\frac{\partial f}{\partial \underline{\sigma}}\right)^{T} \underline{H}}{h+\left(\frac{\partial f}{\partial \underline{\sigma}}\right)^{T} \underline{H}\left(\frac{\partial f}{\partial \underline{\sigma}}\right)}$

and

where $\partial f / \partial \underline{\sigma}$ is the flow vector, $h_{c}$ is a scalar function that depends on the hydrostatic pressure, $\underline{T}^{c r}$ is a transformation matrix that depends on the direction of the cracks formed at a sampling point (Sena-Cruz et al. 2004), and $\widehat{D}^{c r}$ is the constitutive matrix of the set of cracks. In case of one crack per each sampling point,

$\underline{\underline{D}}^{c r}=\underline{D}^{c r}=\left[\begin{array}{cc}D_{I}^{c r} & 0 \\ 0 & D_{I I}^{c r}\end{array}\right]$

where $D_{I}^{c r}$ and $D_{I I}^{c r}$ are the softening modulus of the fracture modes I and II of the smeared cracks, respectively. $D_{I}^{c r}$ is characterized by the stress at crack initiation, $\sigma_{n, 1}^{c r}$ (see Fig. 3), the fracture energy, $G_{f}$, the shape of the softening law and the crack band width, $l_{b}$.

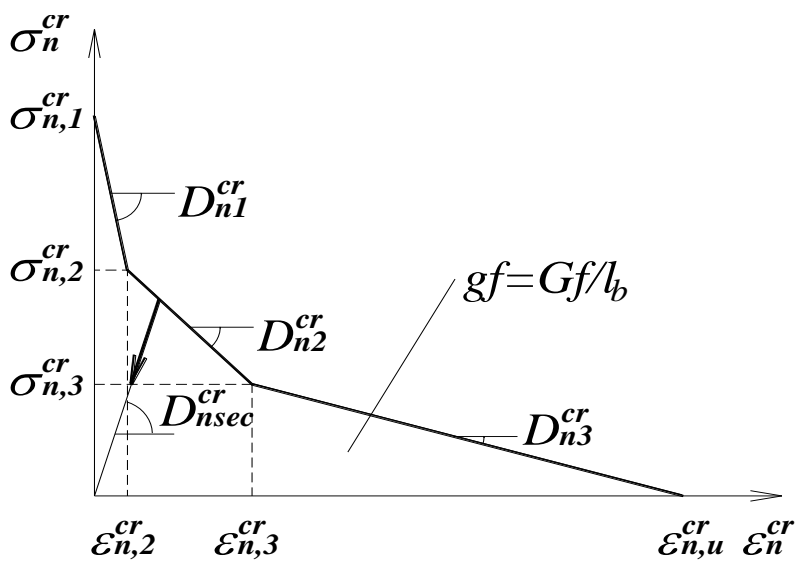

Figure 3. Tri-linear tensile-softening diagram. 
In smeared crack models the fracture zone is distributed over $l_{b}$, which must depend on the finite element geometric characteristics in order to assure that the results of the FEM analysis are not dependent on the finite element mesh (Bazant \& Oh 1983). The fracture mode II modulus, $D_{I I}^{c r}$, of (7) is obtained from (Barros 1995):

$D_{I I}^{c r}=\frac{\left(1-\frac{\varepsilon_{n}^{c r}}{\varepsilon_{n, u}^{c r}}\right)^{p_{1}}}{1-\left(1-\frac{\varepsilon_{n}^{c r}}{\varepsilon_{n, u}^{c r}}\right)^{p_{1}}} G_{C}$

where $G_{C}$ is the concrete elastic shear modulus and $p_{1}$ an integer parameter that can obtain distinct values in order to simulate different levels of concrete shear stiffness degradation (Barros 1995).

In case of cracked concrete with concrete between cracks in linear and elastic state, $\underline{D}_{m b}^{c o}$ is still obtained from (4) replacing $\underline{D}_{m b}^{e p c o}$ by $\underline{D}_{m b}^{e c o}$.

\subsection{Steel constitutive law}

For modeling the behavior of the steel bars, the stress-strain relationship represented in Figure 4 was adopted (Sena-Cruz 2004). The curve (under compressive or tensile loading) is defined by the points $\mathrm{PT} 1=\left(\varepsilon_{s y}, \sigma_{s y}\right), \mathrm{PT} 2=\left(\varepsilon_{s h}, \sigma_{s h}\right)$ and $\mathrm{PT} 3=\left(\varepsilon_{s u}, \sigma_{s u}\right)$, and a parameter $p$ that defines the shape of the last branch of the curve. Unloading and reloading linear branches with slope $E_{s}\left(\sigma_{s y} / \varepsilon_{s y}\right)$ are assumed in the present approach.

\subsection{FRP constitutive law}

A linear elastic stress-strain relationship was adopted to simulate the behavior of NSM CFRP strips applied in the RC slabs.

\section{SIMULATION OF THE TESTS}

\subsection{Materials properties and finite element mesh}

Tables 1 and 2 include the values of the parameters adopted for the characterization of the constitutive models for the concrete and steel, respectively. The CFRP strips, of $10 \times 1.4 \mathrm{~mm}^{2}$ cross sectional area, were assumed as an isotropic material with an elasticity modulus of $160 \mathrm{GPa}$ and null value for the Poisson's coefficient, since the consideration of their real anisotropic properties have marginal influence in terms of their contribution for the behavior of NSM strengthened RC slabs.

Due to the structural symmetry, only half of the slab was considered in the numerical simulations. Figure 5 shows the eight node finite element mesh adopted to discretize the half part of the slab. The

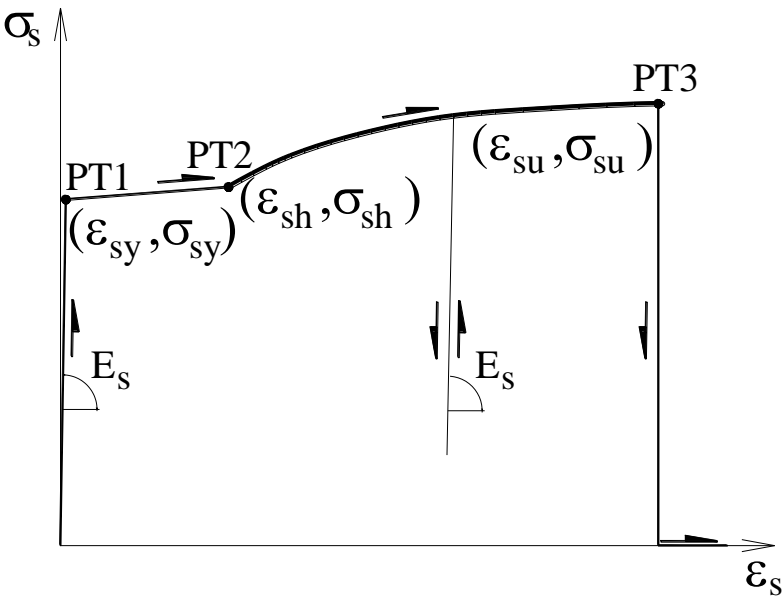

Figure 4. Uniaxial constitutive model of the rebars.

support conditions are also represented in this figure. The slab thickness was discretized in 20 layers.

Table 1. Values of the parameters of the concrete constitutive model.

\begin{tabular}{ll}
\hline Poisson's ratio & $v_{c}=0.15$ \\
Initial Young's modulus & $E_{c}=28000 \mathrm{~N} / \mathrm{mm}^{2}$ \\
Compressive strenght & $f_{c}=40 \mathrm{~N} / \mathrm{mm}^{2}$ \\
Strain at peak compressive strength & $\varepsilon_{c l}=2.2 \times 10^{-3}$ \\
Initial yield surface parameter ${ }^{(1)}$ & $\alpha_{0}=0.4$ \\
Tensile softening diagram ${ }^{(2)}$ & $f_{c t}=1.5 \mathrm{~N} / \mathrm{mm}^{2}$ \\
& $G_{f}=0.05 \mathrm{~N} / \mathrm{mm}$ \\
& $\xi_{l}=0.015$ \\
& $\alpha_{1}=0.6$ \\
& $\xi_{2}=0.2$ \\
& $\alpha_{2}=0.25$ \\
Parameter defining the mode I frac- & $n=2$ \\
ture energy available to the new crack ${ }^{(3)}$ & \\
Shear retention factor (Equation 8$)$ & $p_{1}=2$ \\
Threshold angle ${ }^{(3)}$ & $\alpha_{\text {th }}=30^{\circ}$ \\
Maximum number of cracks per inte- & 2 \\
gration point & \\
\hline${ }^{(1)} \alpha_{0}=\bar{\sigma}_{0} / \bar{\sigma}_{p}$, Sena-Cruz $(2004)$ & \\
${ }^{(2)} f_{c t}=\sigma_{n, 1}^{c r} ; \xi_{1}=\varepsilon_{n, 2}^{c r} / \varepsilon_{n, u}^{c r} ; \quad \xi_{2}=\varepsilon_{n, 3}^{c r} / \varepsilon_{n, u}^{c r} ; \alpha_{1}=\sigma_{n, 2}^{c r} / \sigma_{n, 1}^{c r}$ & \\
$\alpha_{2}=\sigma_{n, 3}^{c r} / \sigma_{n, 1}^{c r}($ see Figure 3$)$ & \\
${ }^{(3)}$ Barros $(1995)$ &
\end{tabular}

Table 2. Values of the parameters of the steel constitutive model (see Figure 4).

\begin{tabular}{lllll}
\hline $\begin{array}{c}\text { Steel bar diameter } \\
(\mathrm{mm})\end{array}$ & $\varnothing 8 \mathrm{~mm}$ & $\varnothing 10 \mathrm{~mm}$ & $\varnothing 12 \mathrm{~mm}$ \\
\hline $\mathrm{P}_{1}$ & $\varepsilon_{\mathrm{sy}}(-)$ & $2.30 \times 10^{-3}$ & $2.70 \times 10^{-3}$ & $2.40 \times 10^{-3}$ \\
& $\sigma_{\mathrm{sy}}(\mathrm{MPa})$ & 421.00 & 446.00 & 445.00 \\
$\mathrm{P}_{2}$ & $\varepsilon_{\mathrm{sh}}(-)$ & $4.42 \times 10^{-2}$ & $3.07 \times 10^{-2}$ & $3.05 \times 10^{-2}$ \\
& $\sigma_{\mathrm{sh}}(\mathrm{MPa})$ & 526.25 & 446.00 & 445.00 \\
$\mathrm{P}_{3}$ & $\varepsilon_{\mathrm{su}}(-)$ & $8.85 \times 10^{-2}$ & $1.31 \times 10^{-1}$ & $1.02 \times 10^{-1}$ \\
& $\sigma_{\mathrm{su}}(\mathrm{MPa})$ & 555.72 & 557.50 & 547.35 \\
\multicolumn{2}{c}{$\mathrm{Es}(\mathrm{GPa})$} & 200.8 & 178.24 & 198.36 \\
\hline
\end{tabular}

\subsection{Results and discussion}

Figures 6 to 9 represent relevant results of the simulations corresponding to the slabs of the SL15 series. The analysis of the simulations of the other series can be found elsewhere (Dalfré \& Barros 2008). 


\begin{tabular}{rl|l|l|l|l|l|l|l|l|l|l|l|l|l|l|l|l|l|l|l|l|l|l|l|l|l|l|l|} 
& 3 & 6 & 9 & 12 & 15 & 18 & 21 & 24 & 27 & 30 & 33 & 36 & 39 & 42 & 45 & 48 & 51 & 54 & 57 & 60 & 63 & 66 & 69 & 72 & 75 & 78 & 81 & 84 \\
\hline
\end{tabular}

$\rightarrow \mathrm{S} 1$

Figure 5. Finite element mesh adopted to discretize the half part of a RC slab.

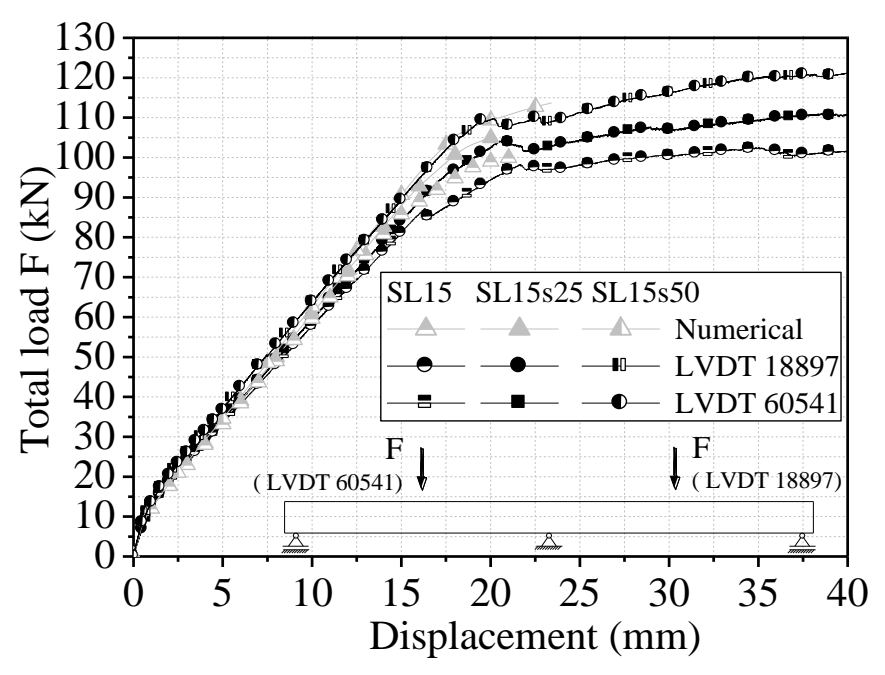

Figure 6. Force-loaded section deflection relationship.

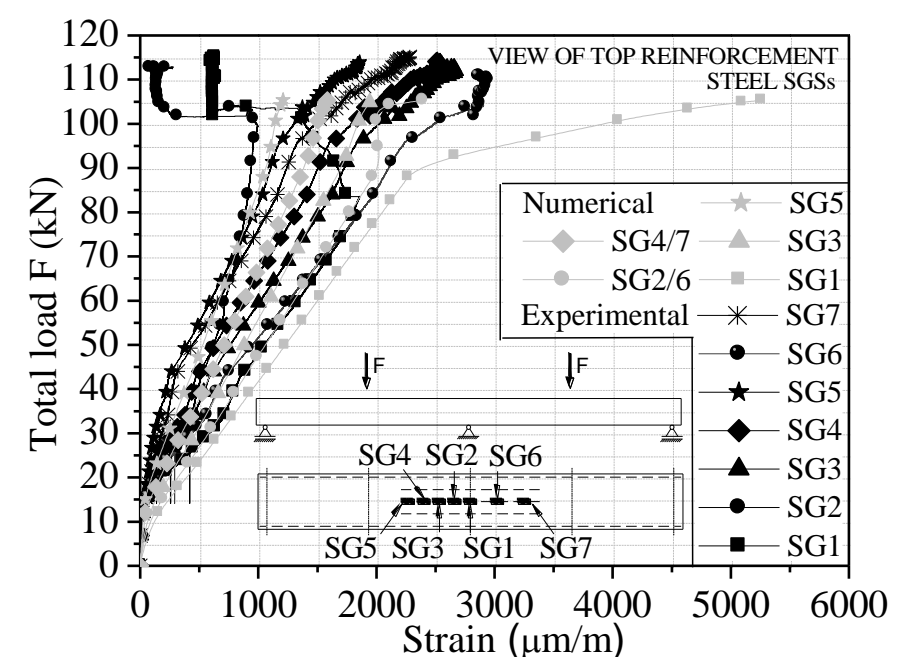

(a)

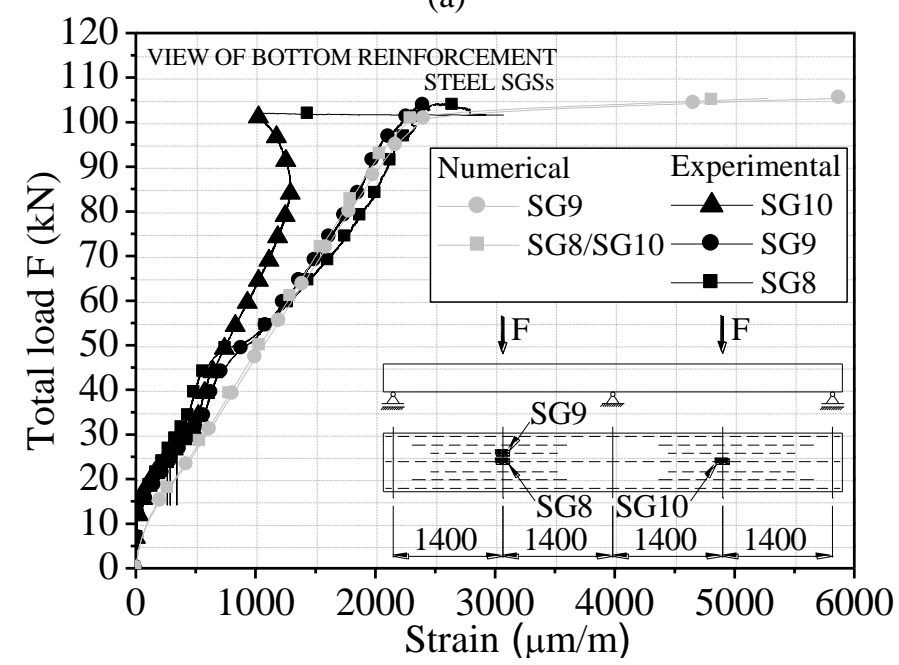

(b)

Figure 7. Force - Steel strain relationships at (a) slab symmetry cross section and (b) loaded section.

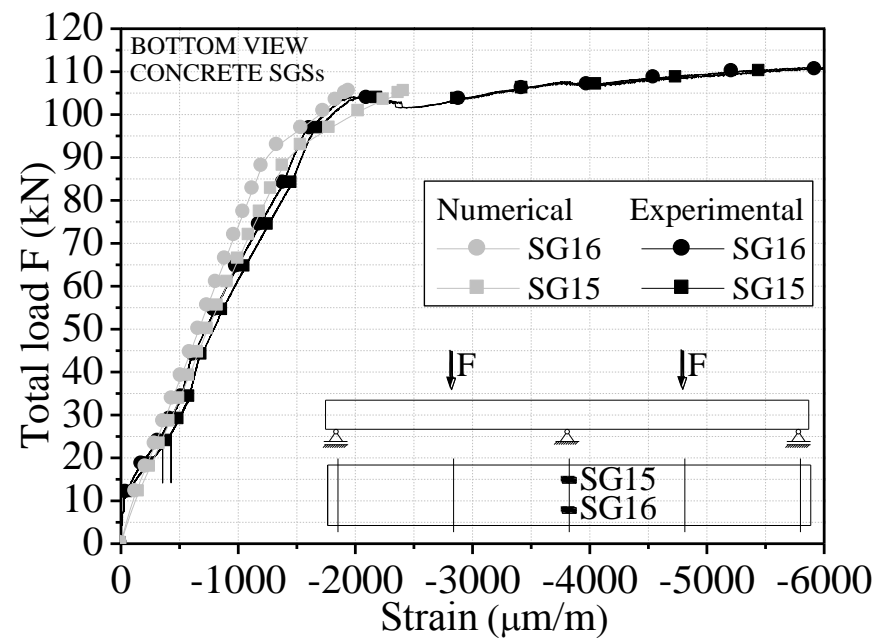

(a)

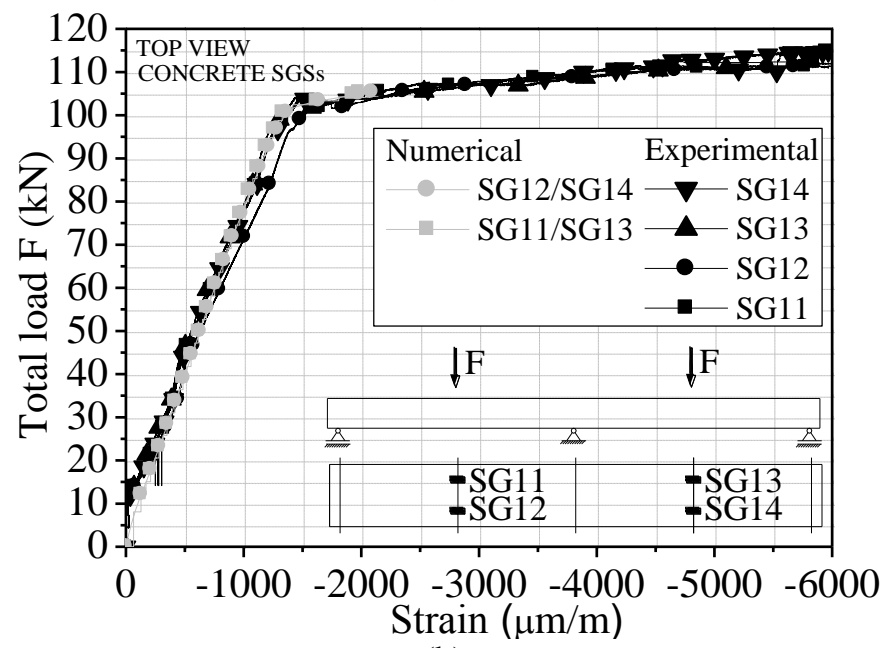

(b)

Figure 8. Force - Concrete strain relationships at (a) slab symmetry cross section and (b) loaded section.

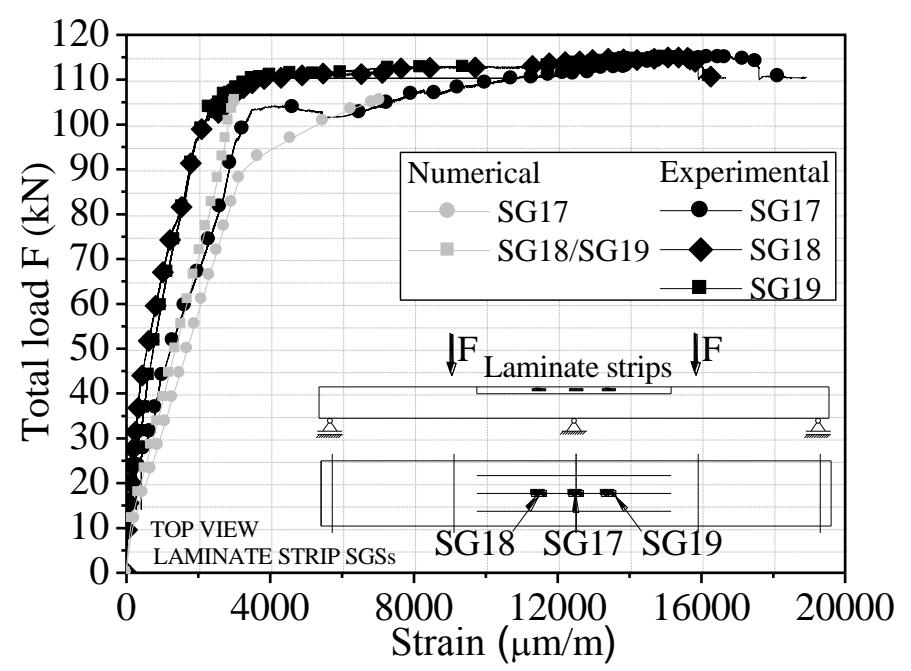

Figure 9. Force-CFRP strain relationship. 
The figures show that the numerical model is able to capture with good accuracy the behavior of the constituent materials of this structural system during the loading process of the tested slabs. Crucial experimental results registered in the monitoring system installed in the constituent materials at the zones of the intermediate support and at the loaded sections (IS and LS, respectively) are included in Table 3.

Table 3. Main results of series SL15.

\begin{tabular}{|c|c|c|c|c|c|c|}
\hline & \multirow[b]{2}{*}{$\begin{array}{l}F_{y}^{I S} \\
(\mathrm{kN})\end{array}$} & \multicolumn{4}{|c|}{ Hinge at intermediate support } & \multirow[b]{2}{*}{$\begin{array}{l}\varepsilon_{f, \max } \\
(\% 0)\end{array}$} \\
\hline & & $\begin{array}{l}u_{y}^{I S} \\
(\mathrm{~mm})\end{array}$ & $\begin{array}{l}\varepsilon_{c}^{I S} \\
(\% 0)\end{array}$ & $\begin{array}{l}\varepsilon_{c}^{L S} \\
(\% 0)\end{array}$ & $\begin{array}{l}\varepsilon_{S}^{L S} \\
(\% 0)\end{array}$ & \\
\hline Reference & 85.29 & 15.85 & -1.22 & -1.53 & 2.20 & ------ \\
\hline SL15s25 & 88.00 & 15.82 & -1.48 & -1.17 & 2.00 & 2.81 \\
\hline \multirow[t]{3}{*}{ SL15s50 } & 96.15 & 16.28 & -1.43 & -1.08 & 2.03 & 2.87 \\
\hline & \multicolumn{6}{|c|}{ Hinge at loaded sections } \\
\hline & $\begin{array}{l}F_{y}^{L S} \\
(\mathrm{kN})\end{array}$ & $\begin{array}{l}u_{y}^{I S} \\
(\mathrm{~mm})\end{array}$ & $\begin{array}{l}\varepsilon_{c}^{I S} \\
(\% 0)\end{array}$ & $\begin{array}{l}\varepsilon_{c}^{L S} \\
(\% 0)\end{array}$ & $\begin{array}{l}E_{S}^{I S} \\
(\% 0)\end{array}$ & $\begin{array}{l}\varepsilon_{f, \max } \\
(\% \mathrm{o})\end{array}$ \\
\hline Reference & 98.00 & 21.50 & -3.77 & -1.91 & 2.45 & ------ \\
\hline SL15s25 & 100.00 & 19.09 & -1.77 & -1.40 & 2.49 & 3.29 \\
\hline \multirow[t]{2}{*}{ SL15s50 } & 100.45 & 18.43 & -1.58 & -1.19 & 2.08 & 3.16 \\
\hline & $\begin{array}{l}F_{\max } \\
(\mathrm{kN})\end{array}$ & $\begin{array}{l}F_{\max } \\
\varepsilon_{f, \max } \\
(\% 0)\end{array}$ & & & & \\
\hline Reference & 98.00 & ------ & & & & \\
\hline SL15s25 & 106.49 & 7.86 & & & & \\
\hline SL15s50 & 118.60 & 7.83 & & & & \\
\hline
\end{tabular}

In this Table, $F_{y}^{I S}$ and $F_{y}^{L S}$ are the total load at the formation of the plastic hinge at IS and LS, $\varepsilon_{c}^{I S}, \varepsilon_{c}^{L S}$ are the average concrete strains at IC and LS, $\varepsilon_{S}^{I S}$ and $\varepsilon_{S}^{L S}$ are the maximum and the average steel bars strains at IS and LS, respectively, $\varepsilon_{f, \max }$ is the maximum strain in the CFRP strips, $F_{\max }$ is the maximum total load up to a concrete compressive strain of $3.5 \%$ in the IS $\left(\varepsilon_{c}^{I S}=3.5 \%\right)$, and $\varepsilon_{f, \max }$ is the maximum strain in the CFRP strips at $F_{\max }$. It was assumed that a plastic hinge was formed when yield strain was attained at the steel bars.

These figures show that, after crack initiation, which occurred at the top surface of the intermediate support for a total load of about $13 \mathrm{kN}$, the slab stiffness decreased significantly, but the elasto-cracked stiffness was almost maintained up to the formation of the plastic hinge at the intermediate support, at a load level of about $85 \mathrm{kN}, 88 \mathrm{kN}$ and $96 \mathrm{kN}$ for the reference, SL15s25 and SL15s50 slabs, respectively.

At these load levels, the maximum concrete compressive strains of the bottom surface at the intermediate support, $\varepsilon_{c}^{I S}$, and of the top surface at the applied load section, $\varepsilon_{c}^{L S}$, are in the ranges $-1.22 \%$ to $-1.48 \%$ and $1.08 \%$ o to $1.53 \%$, respectively. At $F_{y}^{L S}$, the maximum strain of the steel bars of the bottom layer at the applied load section, $\varepsilon_{S}^{L S}$, and the maximum strain at the CFRP strips, $\varepsilon_{f, \max }$, are in the ranges $2.0 \%$ to $2.2 \%$ and $2.81 \%$ to $2.87 \%$, respectively, which indicates that tensile stresses in the laminates are far below its ten- sile strength at the moment of the formation of the plastic hinge at intermediate support.

In fact, the force-deflection relationship (Figure 6) evinces that, up to the formation of the plastic hinge at the intermediate support, CFRP strips did not contribute significantly for the slabs' load carrying capacity. The deflection at $F_{y}^{L S}, u_{y}^{I S}$, was not significantly affected by the presence of the CFRP laminates. Since at the moment of the formation of the plastic hinge at the intermediate support the strains in the steel bars of the loaded sections, $\varepsilon_{S}^{L S}$, are near the steel yield strain (see Table 2), the load increment between the formation of the plastic hinges at intermediate and loaded sections decreased with the increase of the percentage of CFRP laminates. As expected, $F_{y}^{L S}$ was almost equal for the three slabs of SL15 series (98 to $100 \mathrm{kN}$ ), since the deflection at $F_{y}^{L S}$, $u_{y}^{I S}$, decreased with the increase of the CFRP percentage (from $21.5 \mathrm{~mm}$ in the reference slab up to $18.43 \mathrm{~mm}$ in the SL15s50). In the reference slab, at $F_{y}{ }^{L S}$, $\varepsilon_{c} I S$ was higher than the strain at concrete compressive strength $\left(\varepsilon_{c 1}\right.$, see Table 1$)$ and $\varepsilon_{c}^{L S}$ was almost attaining $\varepsilon_{c 1}$, which justifies the formation of the structural mechanism. At $F_{y}^{L S}, \varepsilon_{f, \max }$ was around $3.22 \%$, which is far below the CFRP ultimate strain. However, since $\varepsilon_{c}^{I S}$ and $\varepsilon_{c}^{L S}$ are both lower than $\varepsilon_{c 1}$, the laminates contributed to increase the slab's load carrying capacity. At concrete crushing strain (3.5\% was assumed on the design of the CFRP percentage), the $F_{\max }$ of SL15s 25 and SL15s50 slabs was 106.49 and $118.60 \mathrm{kN}$, respectively, being the corresponding CFRP strains $7.86 \%$ and $7.83 \%$. The contribution of the CFRP laminates for the slab's maximum load carrying capacity was limited due to the occurrence of concrete crushing. In terms of moment redistributing capacity, NSM laminates did not introduce any restriction, and no debond or concrete detachment premature failure modes occurred up to the interruption of the tests.

\section{CONCLUSIONS}

This work presented and discussed the results obtained in a preliminary experimental program dealing with the thematic of moment redistribution capability of two-way RC slabs strengthened according to the NSM technique. The main focus was put on the numerical simulation of the tested slabs, in order to calibrate the constitutive model for its future use on parametric studies, for the evaluation of the influence of relevant parameters on the NSM flexural strength and moment redistribution capability of continuous RC slabs. Since the numerical model was able to capture, with good accuracy, the behavior of the tested slabs, it will be also used to define an extensive experimental work aiming to support the results to be provided by the parametric studies. The comparison between the strains registered experimentally in the CFRP laminates and the strains determined by the 
numerical model shows that it can be assumed a perfect bond between NSM laminates and surrounding concrete.

The contribution of the NSM laminates for the slab's load carrying capacity was limited by the concrete crushing. The NSM strengthened slabs had moment redistribution capability similar of the reference slab. No premature CFRP failure modes were detected up the end of the tests, which occurred at a deflection more than $40 \mathrm{~mm}$.

\section{ACKNOWLEDGEMENTS}

The authors wish to acknowledge the support provided by the "Empreiteiros Casais", S\&P $®$, Secil (Unibetão, Braga) Companies. The study reported in this paper forms a part of the research program "CUTINEMO Carbon fiber laminates applied according to the near surface mounted technique to increase the flexural resistance to negative moments of continuous reinforced concrete structures" supported by FCT, PTDC/ECM/73099/2006. The second author would like to acknowledge the National Council for Scientific and Technological Development $(\mathrm{CNPq})-$ Brazil for financial support for scholarship.

\section{REFERENCES}

ACI Committee 440 (2002). Guide for the design and construction of externally bonded FRP systems for strengthening concrete structures, American Concrete Inst., ACI Committee 440, 118 pp.

Arduini, M., Tommaso, D. A., Nanni, A. (1997), "Brittle Failure in FRP Plate and Sheet Bonded Beams", ACI Structural

Journal, 94 (4), pp. 363-370.

Ashour, A. F., El-Rafaie, S. A., and Garrity, S. W. (2004). Flexural strengthening of RC continuous beams using CFRP laminates, Cement and Concrete Composites, No. 26, pp. 765-775.

Barros, J.A.O., "Comportamento do betão reforçado com fibras - análise experimental e simulação numérica (Behavior of FRC - experimental analysis and numerical simulation)", PhD Thesis, Civil Eng. Dept., Faculty of Engineering, University of Porto, Portugal, 1995 (in Portuguese).

Barros, J.A.O.; Figueiras, J.A., "Nonlinear analysis of steel fibre reinforced concrete slabs on grade", Computers \& Structures Journal, Vol.79, No.1, pp. 97-106, January 2001.

Barros, J. A. O, Fortes, A. S. (2005). Flexural strengthening of concrete beams with CFRP laminates bonded into slits, Cement and Concrete Composites, Vol. 27, No. 04, pp. 471-480.

Barros, J. A. O., Ferreira, Fortes, A. S., and Dias, S. J. E. (2006). Assessing the effectiveness of embedding CFRP laminates in the near surface for structural strengthening, Construction and Building Materials, Vol. 20, No. 07, pp. 478-491.

Bazant, Z.P., Oh, B.H., Crack band theory for fracture of concrete. Materials and Structures, RILEM, 1983, 16(93), 155-177.

Bonaldo, E. NSM technique for the flexural strengthening of $\mathrm{RC}$ slab structures (provisory title). $\mathrm{PhD}$ Thesis, University of Minho, in preparation.

Casadei, P., Nanni, A., Galati, N., Ibell, T., and Denton, S. (2003). Moment redistribution in continuous CFRPstrengthened concrete members: experimental results, In:
International Conference Composites in Construction CCC2003, Cosenza, Italy, September 16-19, pp. 307-312. CEB-FIP Model Code 1990 (1993). Design Code. Thomas Telford, Lausanne, Switzerland.

Concrete Society (2000). Design guidance for strengthening concrete structures using fibre composite materials, Concrete Society Technical Report No 55, The Concrete Society. Century House, Telford Avenue, Crowthorne, Berkshire, UK.

Dalfré, G.M.; Barros, J.A.O., "Numerical simulation of twoway RC slabs strengthened with NSM CFRP laminates", Technical report 08-DEC/E-05, Dep. Civil Eng., University of Minho (in preparation).

El-Refaie S. A., Ashour A. F. and Garrity S. W. (2003a). Sagging and hogging strengthening of continuous reinforced concrete beams using CFRP sheets, ACI Structural Journal, Vol. 100, No. 4, July-August, pp. 446-453.

El-Refaie S. A., Ashour A. F. and Garrity S. W. (2003b). CFRP strengthened continuous concrete beams, Structures and Buildings, Vol. 156, No. 4, November, pp. 395-404.

Fédération Internationale du Béton (FIB). (2001). "Externally bonded FRP reinforcement for RC structures." Bulletin 14, Lausanne, Switzerland.

Hassan, T., and Rizkalla, S. (2003). Investigation of bond in concrete structures strengthened with near surface mounted carbon fiber reinforced polymer strips, Journal of Composites for Construction, Vol. 07, No. 03, pp. 248-257.

Liu, I. S. T., Oehlers, D. J., Seracino, R., and Ju, G. (2006a). Moment redistribution parametric study of CFRP, GFRP and steel surface plated RC beams and slabs, Construction and Building Materials, No. 20, pp. 59-70.

Liu, I. S. T., Oehlers, D. J., and Seracino, R. (2006b). Tests on the ductility of reinforced concrete beams retrofitted with FRP and steel near-surface mounted plates, Journal of Composites for Construction, Vol. 10, No. 02.

Oehlers, D. J., Ju, G., Liu, I. S. T., and Seracino, R. (2004a). Moment redistribution in continuous plated $\mathrm{RC}$ flexural members. Part1: neutral axis depth approach and tests, Engineering Structures, No. 26, pp. 2197-2207.

Oehlers, D. J., Liu, I. S. T., Ju, G., and Seracino, R. (2004b). Moment redistribution in continuous plated RC flexural members. Part2: Flexural rigidity approach, Engineering Structures, No. 26, pp. 2209-2218.

Oehlers, D. J., Campbell, L., Haskett, M., Antram, P., and Byrne, R. (2006). Moment redistribution in RC beams retrofitted by longitudinal plating, Advances in Structural Engineering, Vol. 9, No. 2, April, pp. 257-264.

Sena-Cruz, J.M. "Strengthening of concrete structures with near-surface mounted CFRP laminate strips." PhD Thesis, Department of Civil Engineering, University of Minho, (2004).

Sena-Cruz, J.M.; Barros, J.A.O.; Azevedo, A.F.M., "Elastoplastic multi-fixed smeared crack model for concrete", Technical report 04-DEC/E-05, Dep. Civil Eng., University of Minho, $70 \mathrm{pp}$, June 2004.

Sena-Cruz, J.M.; Barros, J.A.O.; Azevedo, A.F.M.; Ventura-Gouveia, A., "Numerical simulation of the nonlinear behavior of RC beams strengthened with NSM CFRP strips", CMNE/CILAMCE, FEUP, Porto, 13, 13-15 June, 2007.

Täljsten, B., Carolin, A., and Nordin, H. (2003). Concrete structures strengthened with near surface mounted reinforcement of CFRP, Advances in Structural Engineering, Vol. 06, No. 03, August, pp. 201-213. 